\title{
Teaching the Use of Cost-Benefit Reasoning in Everyday Life
}

\author{
Richard P. Larrick, James N. Morgan, and \\ Richard E. Nisbett \\ The University of Michigan
}

Abstract-Our research shows that people can apply the costbenefit rules of microeconomic theory to their everyday decisions. Two populations were examined: (a) people who had previously received extensive formal training in the rules and (b) naive subjects who were randomly assigned to receive brief training in the rules. Training affected reasoning and reported behavior in both populations. The results indicate that extremely general rules govern choices across a wide range of domains and that use of the cost-benefit rules can be improved through training.

Do people think about leaving bad movies, taking losses on investments, and demolishing outdated buildings in the same way, relying on the same inferential rules? Are there general rules of choice that guide people's decisions across a broad range of domains? If so, can the nature of these rules be altered by instruction?

Economists have long assumed that a set of abstract rules of choice exists, and that people make choices according to those rules across the economic spectrum from consumer choices to decisions about time use (Becker, 1976). On the other hand, many psychologists share Thorndike's (1906) view that people's behavior is governed by domain-dependent rules that do not generalize across situations that are very different from one another. Even among psychologists who believe that people have domain-independent rules, a pervasive opinion originating with Piaget is that such rules can only be learned by selfdiscovery methods and cannot really be taught in a formal way (Brainerd, 1978; Newell, 1980).

In this paper, we examine whether people use abstract rules in making choices and whether these principles can be taught so that people will use them across a wide range of situations. We first sketch the cost-benefit model of choice and show that there is ample evidence that people depart from it in their everyday choices. We next present original evidence about differential rule usage, comparing people trained in the use of the normative rules with those who are less trained. Finally, we present evidence about the trainability of people by relatively brief interventions, about the degree of domain specificity of training, and about the durability of training.

\section{COST-BENEFIT RULES OF CHOICE}

The basic assumption underlying the microeconomic model of choice is that people choose actions that maximize their

Correspondence and reprint requests to Richard E. Nisbett, 5261 ISR, The University of Michigan, Ann Arbor, MI 48106. overall welfare. The model assumes people are confronted by a set of actions, each of which is associated with outcomes that will occur with some probability. Each of these outcomes has a value to the person that can be compared with the values of the other outcomes by converting the values to a single scale (for example, dollars). Three principles follow from this model. (a) The greatest net benefit principle, which states that the action with the greatest positive difference between the total benefit and total cost of its outcome should be chosen from the set of possible actions. (b) The sunk cost principle, which states that only future benefits and costs should be considered when making a choice. (c) The opportunity cost principle, which states that a cost of undertaking a given course of action is foregoing the expected net benefits associated with other courses of action.

These principles may seem incomplete to readers familiar with standard textbook cost-benefit analysis (Mishan, 1976; Morgan \& Duncan, 1982). We eliminated certain principles from the list of inferential rules of choice because they were either derivable from the principles listed above, or because they were not sufficiently general to apply to all choice situations. Also, these cost-benefit rules certainly are not exhaustive of the principles that guide choice. Moral, esthetic, and social principles may compete with the cost-benefit rules, and humanistic values may be included as costs and benefits in the economic calculus. Thus, departures from economic reasoning could be due to people's favoring humanistic values or principles rather than ignorance of the normative rules. We will return to the question of whether noneconomically trained people know cost-benefit reasoning but are more likely to favor humanistic values, or whether they are actually less likely to know and use cost-benefit reasoning.

\section{Lay Use of the Cost-Benefit Rules of Choice}

A fundamental assumption of economics is that people make choices consistent with the cost-benefit rules (Friedman, 1953). There now exists, however, a good deal of research indicating that people violate the maximization rules of microeconomics. An early dissenting view introduced by Simon (1955) proposed that people do not attempt to maximize utility but simply attempt to attain some minimal level of satisfaction. In the past few decades, many empirical violations of expected utility theory have been documented, including violations of the independence axiom (Allais, 1953) and transitivity (Lichtenstein \& Slovic, 1971; Tversky, 1969) and various violations of utility maximization (Kahneman \& Tversky, 1979). These critiques 
have buttressed the psychologists' case against the view that a single, coherent set of abstract rules underlies choice behavior and have revealed serious shortcomings in choice behavior that produce nonoptimal outcomes. We shall focus on several economic traps that occur when people fail to use the sunk cost and opportunity cost principles.

\section{Violations of the Sunk Cost Principle}

A particularly clear case of an economic trap occurs when people consider past investments of money, effort, or time in their current decisions. For instance, imagine you have bought $\$ 15$ tickets for a basketball game weeks in advance, but on the day of the game it is snowing and the star player you wanted to see is sick and will not play. The game is no longer of much interest to you. Do you decide to go to see the game or stay home and forget the money you have spent? (Adapted from Thaler, 1980.)

In these circumstances, some people will go to the game for the primary reason that they spent a large amount of money on it. What is wrong with this? Once the money is sunk, going to the game will not enable the person to get his or her "money's worth," but will simply inflict additional costs of a dangerous trip and a boring game. The sunk cost principle prescribes that a decision maker should consider only the benefits and costs that are going to be incurred from the time of the decision forward and ignore the past costs. To make it easier to ignore past costs, the person can do a thought experiment: Would I go to the game if someone called me on the day it was scheduled and offered me a free ticket? If not, then a sunk cost trap should be suspected.

The sunk cost effect has been demonstrated in studies by Arkes and Blumer (1985), who proposed that an important cause of the trap is peoples' ignorance of the normative sunk cost rule and their reliance on the generally effective rule of "waste not, want not." The "waste not, want not" rule is normative for economic choices that involve decisions about the future. People would be acting counternormatively if they deliberately chose to expend resources in pursuit of some benefit they intended to waste. But the rule is not normative for economic decisions involving irretrievable past costs. Note that this interpretation implies that people do operate with highly abstract rules of choice, but that these rules may differ from the normative ones.

A second type of economic dilemma that occurs when people fail to ignore sunk costs is a situation we call the extra cost trap. In this type of trap, people abandon an enjoyable activity because they are attending to past costs. For instance, imagine you are on your way to see one of your favorite plays for which you have bought a ticket in advance, but when you get to the theater, you discover you have lost the ticket. (Adapted from Tversky \& Kahneman, 1981.) Would you decide to buy a second ticket or to skip the play? Some people in this situation might skip the play because they feel that they have already spent $\$ 20$ on a ticket and the play is not worth $\$ 40$ (which is the total cost if the person buys a second ticket). They feel that it is a waste to spend twice as much on a play ticket as it is worth. The sunk cost principle, however, prescribes that you ignore the sunk $\$ 20$ ticket, and decide whether the future benefits of seeing the play exceed the future cost, which is $\$ 20$, the price of a second ticket. A thought experiment is also helpful here: Would you still go to the play if you had lost $\$ 20$ in cash on the way to the theater? The answer is probably yes, because the value of the performance has not been affected.

\section{Violations of the Opportunity Cost Principle}

Another type of economic trap occurs when people ignore the opportunities they forego by choosing one course of action rather than another. For instance, imagine that you have paid off the mortgage on your home, and you are deciding whether to keep your house or move into an apartment. Many people compare the out-of-pocket costs of living in a house with those of living in an apartment and conclude that keeping the home is much cheaper than renting. However, by tying up wealth in a house, a person foregoes interest income, which is often more than enough to offset the difference in the out-of-pocket costs between owning and renting. The waste not, want not principle leads people to feel that it is a waste to "throw away" money on rent when they could live in their own home for "free."

Research on opportunity costs establishes that people often fail to calculate opportunity costs when they are unstated (Neumann \& Friedman, 1980) and tend to underestimate them when they are explicitly stated but small (Hoskin, 1983). Additional evidence that people have poor understanding of opportunity costs is provided by research on buying and selling behavior in experimental markets, which shows that the lowest amount of money subjects are willing to accept for a good is higher than the highest amount they are willing to pay for the same good (Kahneman, Knetsch, \& Thaler, in press). An analogous discrepancy occurs in people's use of time. People will often perform a service for themselves (for example, mowing the lawn) even though the amount they could earn performing some other activity would be higher than the amount they would have to pay for someone else to perform the service. An awareness of opportunity costs should lead people to pay more for the services of others and to invest in time-saving devices.

\section{Evidence that People use Inferential Rules}

Taken as a whole, the evidence indicates that the economic model is wrong in assuming that people act as though they use the abstract normative rules. Indeed, the findings are consistent with the view that people do not use abstract rules of any type but rely on highly concrete domain-dependent rules.

In a recent series of studies, however, Nisbett and his colleagues have found that people do use abstract, domainindependent inferential rules to reason about certain everyday problems, and that their reasoning can be improved by formal instruction (for a review see Nisbett, Fong, Lehman, \& Cheng, 1987). The rules examined include statistical rules (Fong, Krantz, \& Nisbett, 1986; Fong \& Nisbett, in press; Kunda \& Nisbett, 1986; Nisbett, Krantz, Jepson, \& Kunda, 1983), as well as causal and contractual rules (Cheng \& Holyoak, 1985; Cheng, Holyoak, Nisbett, \& Oliver, 1986; Cheng \& Nisbett, 1990; Morris \& Nisbett, 1990). But these rules represent only a 
Teaching Rules of Choice

portion of the range of possible inferential rules that people use for everyday decisions. More importantly, judgmental rules af fect behavior only indirectly. In the following work, we wanted to extend the inferential rules findings to the choice domain and examine whether knowledge of inferential rules affects actual behavior.

\section{DISCIPLINE DIFFERENCES IN THE USE OF THE NORMATIVE RULES OF CHOICE}

In the first study, we examined whether professional training in economics affects a wide range of behaviors governed by normative choice principles. We compared the self-reported decisions and behaviors of economics professors with those of biology and humanities professors.

\section{Study 1}

\section{Subjects}

The subjects were 126 professors from the departments of economics, biology, art history, and Romance languages at the University of Michigan. Telephone interviewers stated that "we are interested in finding out how faculty feel about some choices that may confront the university over the next few years, and we're also interested in some personal decisions faculty have made. In addition, we're interested in the relationship between the two." The overall volunteer rate was $88 \%$.

\section{Stimulus materials}

The survey contained two types of questions-reasoning questions and behavioral self-report questions. Six reasoning questions asked about University policy issues and two about international policy issues. The questions were designed to draw on the use of three normative principles: the sunk cost principle, the opportunity cost principle, and the net-benefit principle. Each problem presented subjects with two arguments-one that expressed a normative principle and one that contradicted it. The subjects were then asked which view they agreed with more. An example of each type of problem is given in Figure 1. (The scoring is indicated for each alternative on the extreme left, with higher numbers indicating more normative answers.)

For the sunk cost problem about replacing versus renovating the old hospital, the normative analysis indicates that the original cost of building the hospital is irrelevant to the current decision (sunk), and the only concern should be the future costs of renovation versus new construction. For the opportunity cost problem about scholarship aid, the normative analysis indicates that, as the opportunity costs of going to college increase for students, universities will have to increase their financial aid in order to maintain their attractiveness to students. And for the net-benefit problem involving purchasing blood, the net-benefit principle implies that both parties should choose their most preferred action, which for this problem is to engage in the transaction.

The behavioral section of the survey measured various consumer and financial decisions the professors had made in the past. The initial questions in this section were used to control

\section{SUNK COST PROBLEM (UNIVERSITY POLICY)}

As you may know, the university is currently planning the demolition of the old hospital. The argument has been made, however, that the building was extremely expensive to build for its time and that it is wasteful simply to destroy it. The counterargument is that renovation in the case of this building is more expensive than construction. Do you tend to favor: renovation;

(1.00)__demolition; or

$(0.50) \ldots$ you do not have an opinion.

\section{OPPORTUNITY COST PROBLEM (UNIVERSITY POLICY)}

Some financial planners for the university anticipate that jobs for young people may soon be much more plentiful than in the recent past, for the simple reason that a much smaller fraction of the population is in the younger age group. One implication is that pay will increase for entry level jobs in all kinds of industries. The argument has been made that the university should respond to this situation by offering more money for scholarships in order to lure low income students away from starting work and toward continuing their education. Do you feel:

(1.00)___scholarships should be kept competitive with salaries;

$(0.00) \_$_ scholarships should simply maintain pace with inflation and not respond to competitive inducements;

$(0.50) \_$you do not have an opinion.

\section{NET-BENEFIT PROBLEM (INTERNATIONAL POLICY)}

As you may know, there are continuing problems with assuring that blood supplies for patients are free of all viruses. The suggestion has recently been made to purchase blood from Asians for use in the West, on the grounds that many of the most dangerous viruses, including AIDS, are less common there. Many citizens of relatively poor Asian countries would be happy to have the extra cash; however, others have argued that such a practice would be an inappropriate form of exploitation. Do you tend to:

(1.00)__favor the idea strongly;

$(0.75) \ldots$ _favor it somewhat;

$(0.50) \_$have no preference;

$(0.25) \_$_ oppose the idea somewhat;

$(0.00) \ldots$ _oppose it strongly.

Fig. 1. University and international policy problems given to university faculty in Study 1 
Table 1. Economic policy preferences and reported behavior as a function of academic discipline

\begin{tabular}{lcccccc}
\hline \hline & \multicolumn{5}{c}{ Discipline } \\
\cline { 2 - 6 } \multicolumn{1}{c}{ Index } & Economics & Biology & Humanities & $\begin{array}{c}\text { Regression } \\
\text { Coefficient }\end{array}$ & $p$-value \\
\hline Reasoning about policy & .73 & .58 & .54 & $(.27)$ & .01 \\
Discontinuing activities & .42 & .24 & .22 & $(.35)$ & .001 \\
Foregoing activities & .24 & .16 & .14 & $(.16)$ & .15 \\
Personal decisions & .71 & .57 & .49 & $(.22)$ & .05 \\
Time-saving activities & .61 & .48 & .52 & $(.28)$ & .01 \\
Overall behavior & .50 & .36 & .34 & $(.41)$ & .001 \\
Overall reasoning and behavior & .61 & .47 & .44 & $(.39)$ & .001 \\
\hline
\end{tabular}

Note. Scores range from 0 to 1.0, with higher scores indicating more normative responses. Means are unadjusted. Biologists and humanists were included in a single, noneconomist category in the analyses. Regression coefficients are the standardized coefficients from the multiple regression analysis controlling for salary, age, and gender (the analyses for discontinuing and foregoing activities were also controlled for consumption opportunities). The $p$-values are from the multiple regression analyses. Because people rarely reported foregoing consumer activities, those activities that were skipped by less than ten percent of the subjects were excluded from the foregone activities index. The overall behavior index is an average of the four behavior indices. The overall reasoning and behavior index is an average of the policy index and overall behavior index.

for the opportunities professors had to display either normative behavior or trap behavior. These questions asked how often in the past year the subject had engaged in seven different consumer activities, such as going to movies. The remainder of the questions in this section assessed whether the subjects behaved in accordance with the normative principles. Subjects were asked the following four types of questions, each of which was scored as a 1 , for a behavior consistent with the normative principles, or a $\mathbf{0}$, for a behavior that could indicate trap reasoning.

1. Discontinuing activities after incurring a sunk cost. "In the past five years have you ever started one of the following items and then not finished it?" There followed a list of seven consumer activities (e.g., a movie, a restaurant meal, a sports event).

2. Foregoing activities after incurring a sunk cost. "In the past five years have you ever bought one of the following items and then not used it?" There followed seven consumer activities.

3. Personal decisions involving sunk costs or opportunity costs. For example, "Have you ever dropped a research project because it was not proving worthwhile?" and "Have you ever had more income withheld from your paycheck than you actually owed in taxes in order to get a large refund?"

4. Opportunity costs of time use. For example, "Do you do some of your own yard work?" and "Do you own a microwave?"

The survey also asked about a variety of demographic variables, including age. Information about salaries was obtained from published University records.

\section{Results}

The goal was to examine whether economics training is related to choice. Because there were no theoretical reasons to distinguish biologists and humanists, they were combined in the statistical analyses to form a single, noneconomist category. (The means for both biologists and humanists are reported to verify that this procedure was justifiable.) The survey responses were used to create one reasoning and four behavioral indices that were averages of individual questions. All of the indices were analyzed using multiple regression, which controlled for salary, age, and gender. ${ }^{1}$ The unadjusted means for each group are reported in Table 1 along with the standardized coefficients and $p$ levels for the discipline variable.

It may be seen in Table 1 that economists' reasoning on the university and international policy questions was more in line with cost-benefit rules than was that of biologists and humanists. This pattern was found for the net-benefit questions $(p<$ $.05)$, and for the opportunity cost questions $(p<.05)$ and a trend was found for the sunk cost questions $(p<.15)$.

It also may be seen in Table 1 that economists were more likely to behave in line with the cost-benefit rules. First, economists reported discontinuing a significantly greater percentage of the consumer activities than the biologists and the humanists. Second, economists tended to report foregoing a greater percentage of the consumer items than the biologists and the humanists, although this was not significant. Third, economists were more likely than biologists and humanists to report that they ignored sunk costs or attended to opportunity costs in their personal decisions. For instance, they were more likely to have

1. Analyses of the behavioral indices about discontinuing and foregoing consumer activities also controlled for consumption opportunities. An opportunity index was calculated by standardizing the number of times subjects reported engaging in each consumer activity and then averaging these scores for each subject. 
dropped a research project because it was not proving worthwhile. (It is interesting to note that economists were not simply more likely to drop projects. All three disciplines gave the same answer on average to the question "have you ever dropped a research project because of a lack of funding?') Finally, economists participated in a greater number of time-saving activities.

Training in economics was strongly related to reasoning and behavior across a wide range of choices. Economics thus is a system of rules of choice that is practiced by its adherents as well as preached. ${ }^{2}$ Additional analyses indicate that the discipline difference is not due to economists favoring cost-benefit rules over humanistic rules or values (Larrick et al., 1990). When the questions on the survey were categorized according to whether there was a conflict between cost-benefit rules and humanistic rules (for example, the question about buying blood from poor Asians) or there was no conflict (for example, discontinuing a video), economists were more likely to give costbenefit reasoning in both instances. Thus, noneconomists are not just applying other humanistic principles or values. Rather, noneconomists are less likely to apply the cost-benefit rules than are economists.

These results support our claim that training produces knowledge of the normative rules, but we cannot rule out the alternative explanation that economists are predisposed to behave and reason in accordance with the normative rules before they actually receive any training. In order to show that selfselection is not a necessary condition for acquisition of the normative rules, we brought naive undergraduates into the laboratory and trained them on the sunk cost principle.

\section{TEACHING THE NORMATIVE RULES OF CHOICE}

The first of two training studies examined the effects of instruction on answers to questions about choice. It also examined whether domain of training (financial problems or nonfinancial problems) affects how well people use the principles in a given domain. A finding that domain is not important would suggest that economic principles are readily generalized from examples to become abstract inferential systems. Subjects were brought into the laboratory and trained for half an hour on the sunk cost principle and the derivative extra-cost principle.

\section{Study 2}

Seventy-nine subjects from the University of Michigan's paid subject pool were assigned randomly to receive financial training, nonfinancial training, or no training. In the training sessions, materials employed either exclusively financial or nonfinancial examples and terminology. A typical training prob-

2. For all of the findings, the effect of training existed independent of the effect of salary, though it is interesting to note that salary also had an independent effect (Larrick, Nisbett, \& Morgan, 1990). Answers to both policy and behavioral questions were more in line with cost-benefit principles for subjects with higher salaries $\left(\beta_{s}=.33\right.$ and .23$)$ and this was especially true for noneconomists $\left(\beta_{s}=.43\right.$ and .33$)$. lem is the lost theater ticket question presented in the introduction (which is a financial, extra cost problem). Following training, subjects were given a test containing both financial and nonfinancial instances of sunk cost and extra cost problems. An example of a financial, sunk cost problem is the basketball question presented in the introduction. The nonfinancial problems were similar to financial problems in structure but the resource in question was time or effort rather than money. ${ }^{3}$

When they were tested, trained subjects were instructed, first, to use the reasoning of the economic principles to solve the problems for which they thought the principles were appropriate; and second, to indicate whether they agreed or disagreed with this reasoning. In the control sessions, subjects received no training materials. They were asked to complete a "decisionmaking" test. They were instructed to think carefully about the problems and to write down what they thought they would do.

Answers were coded for normativeness of choice, measuring the extent to which a subject's choice agreed with the choice prescribed by the appropriate economic principle, and for normativeness of reasoning, measuring the extent to which a subject's reasoning accurately employed the appropriate economic principle. In order for an answer to be normative, it had to state either that the past costs are irrelevant or that only future benefits and costs are relevant. For an answer to be counternormative, it had to state that the previous costs are a reason for choosing the counternormative action. Responses were coded as (a) counternormative, (b) mixed or unstated, or (c) normatively correct. ${ }^{4}$ Note that the sunk cost and extra cost problems serve as catch trials for each other, because the normative choice in the former situation is to abandon the activity and the normative response in the latter situation is to persevere. Thus, in order to reason correctly, subjects had to go beyond stating that past costs are irrelevant to actually comparing future costs with future benefits. This prevented subjects from relying on a simple rule of thumb such as always quitting after a sunk cost.

The mean scores for subjects' own choice and reasoning measures for each cell are given in Table 2 . A $3 \times 2 \times 2$ (Training $\times$ Domain $\times$ Principle) ANOVA, with repeated measures on the last two factors, showed that trained subjects chose more normatively, $F(2,76)=9.26, p<.001$, and reasoned more normatively, $F(2,76)=24.55, p<.001$, than untrained subjects. $^{5}$

Domain specificity of training would be indicated by an interaction such that financially trained subjects performed more normatively on financial problems than on nonfinancial problems, and nonfinancially trained subjects did the opposite. This pattern of means, however, was not obtained for either measure. Indeed, there appears to be complete domain independence of training effects.

3. For example, in one nonfinancial problem, the protagonists have driven a great distance to a Western park of little interest, thinking that it was another park of much more interest. The question is whether they should stay and see the meager attractions of the park or drive on immediately to another park, The sunk cost lure is to stay and see the uninteresting park in order to justify the time spent getting there.

4. Coders agreed on $92 \%$ of the answers. The disputed answers were coded through consensus.

5. All significance levels are for two-tailed tests. 
Table 2. Mean scores for normativeness of choice and normativeness of reasoning

\begin{tabular}{|c|c|c|c|c|c|}
\hline \multirow[b]{2}{*}{$\begin{array}{l}\text { Training } \\
\text { Condition }\end{array}$} & \multicolumn{5}{|c|}{ Problem Type } \\
\hline & $n$ & $\begin{array}{l}\text { Financial } \\
\text { Sunk Cost }\end{array}$ & $\begin{array}{l}\text { Financial } \\
\text { Extra Cost }\end{array}$ & $\begin{array}{l}\text { Nonfinancial } \\
\text { Sunk Cost }\end{array}$ & $\begin{array}{c}\text { Nonfinancial } \\
\text { Extra Cost }\end{array}$ \\
\hline \multicolumn{6}{|c|}{ Normativeness of Choice } \\
\hline Financial & 25 & 2.28 & 2.90 & 2.60 & 2.56 \\
\hline Nonfinancial & 33 & 2.35 & 2.91 & 2.69 & 2.59 \\
\hline Control & 21 & 1.90 & 2.31 & 2.43 & 2.26 \\
\hline \multicolumn{6}{|c|}{ Normativeness of Reasoning } \\
\hline Financial & 25 & 2.38 & 2.62 & 2.48 & 2.50 \\
\hline Nonfinancial & 33 & 2.59 & 2.60 & 2.45 & 2.36 \\
\hline Control & 21 & 1.90 & 2.09 & 2.00 & 2.00 \\
\hline
\end{tabular}

The results show that training people only briefly on an economic principle significantly alters their solutions to hypothetical economic problems. Moreover, training effects generalize fully from a financial domain to a nonfinancial one and vice versa.

\section{Study 3}

The first training study could not assess whether subjects retained the principles they learned nor could it assess whether the subjects applied the principles outside the laboratory. These issues were addressed in Study 3, which had a laboratory phase and a follow-up phase. In the laboratory phase, a new group of subjects was trained on the sunk cost and extra cost principles. In the follow-up phase, subjects were contacted by phone one month after training, and, under the guise of a consumer survey, they were asked questions about their consumer decisions and their opinions on University policy. Because all of the questions tacitly involved sunk cost issues, the subjects' responses were an indication of the degree to which they behaved or reasoned according to the normative principles.

Another purpose of this second training study was to test the view that laypeople use what they take to be an economically correct principle, namely the "waste not, want not" rule. In the laboratory phase, all subjects were asked to indicate the response they thought economists would give as well as their personal response for each problem. We anticipated that subjects would misidentify the rule that economists would invoke.

\section{Laboratory methods and results}

Eighty-nine undergraduates from the University of Michigan's introductory psychology pool participated to receive credit toward a research requirement. Trained subjects received both financial and nonfinancial materials. Untrained subjects received a superficial description of cost-benefit analysis, which briefly stated that people should choose the action with the greatest positive difference between benefits and costs and should pay attention only to future benefits and costs when they are making a decision. The same test problems were used as before. The responses, however, were no longer open-ended but were restricted to four types of action-reasoning combinations, as shown in Figure 2 for the sunk cost problem concerning basketball tickets.

The subjects' understanding of the normative principle was

1. Normative alternative (Normative actionnormative reasoning). "I would skip the game because it's less interesting than when I bought the tickets and it's more difficult to get to. No matter what I do, I can't get my $\$ 30$ back, so why should I make matters worse by going to the game? l'd forget the $\$ 30$ and find something else to do."

2. Trap alternative (Trap action-trap reasoning). "I would go to the game because, even though it's less interesting and more difficult to get to, it would be wrong to waste the $\$ 30$ I spent on the tickets. I probably wouldn't go if someone gave me the tickets, but since I have bought them, it's important not to waste money-if I didn't go to the game, I couldn't get my money's worth."

3. Mixed Trap alternative (Normative action-trap reasoning). "I would skip the game because, if I were in an accident, someone could be seriously hurt, and I'm sure that the damage to my car would add up to more than $\$ 30$. The game is no longer interesting and the cost of being in an accident is far more than the cost of the tickets, so I would stay home."

4. Noneconomic alternative (Trap actionnon-economic reasoning). "I would go to the game despite the fact that it's less interesting and more difficult to get to. When I bought the tickets, I should have realized that it might be snowing and that the other team might no longer be in contention for the playoffs. If it was worth going in the first place, it still is."

Fig. 2. Multiple choice responses for the basketball problem used in Study 3 
measured by the question "Which response would an economist be most likely to choose?" Each subject was given a score corresponding to the percentage of the eight problems for which the subject chose a particular alternative as the economic response. These means are presented in Table 3 . The $2 \times 4$ (Training by Alternative) ANOVA revealed that the two-way interaction was significant, $F(3,261)=122.18, p<.001$. The trained subjects were far more likely to choose the normative alternative as the economic response and far less likely to choose the trap response. These results indicate that untrained subjects overwhelmingly misidentify the economist's reasoning principles. Apparently they take the "waste not, want not" principle underlying the trap alternative to be normative.

The subjects' own reasoning was measured by the question "Which response would you choose?" The mean scores showing how often each alternative was chosen as a personal response are given in Table 3 . The $2 \times 4$ (Training by Alternative) ANOVA revealed that the two-way interaction was significant, $F(3,261)=7.95, p<.001$. The trained subjects chose the normative alternative as their personal response for $44 \%$ of the problems compared to $28.6 \%$ for the untrained subjects, $t(87)=$ $4.77, p<.01$. The trained and untrained subjects did not differ in how often they chose the trap alternative as their own response $(11.1 \%$ and $13.1 \%$, respectively). The trained subjects, however, chose the mixed trap response significantly less often $(M=30.1 \%)$ than the untrained subjects $(M=38.6 \%), t(87)=$ $2.26, p<.05$. Whereas the modal answer for the trained subjects was the normative alternative, the modal answer for the untrained subjects was the mixed trap alternative.

It is important to note that untrained subjects were more likely to prefer the normative answer for themselves than they were to pick it as the economist's answer, $M s=28.6 \%$ vs $16.9 \%, t(44)=3.30, p<.01$. This suggests the ironic conclusion that our subjects would feel that they were being uneconomical in choosing the answer actually preferred by economists.

\section{Follow-up methods and results}

A telephone survey was conducted four to six weeks after subjects participated in the laboratory training. Several steps were taken to reduce the possibility of suspicion. ${ }^{6}$ Eighty subjects were interviewed, of which 40 were trained and 40 untrained. The follow-up survey asked a variety of behavioral and reasoning questions that were designed to detect the subject's use of the sunk cost principle. In the first section of the survey, subjects were asked questions about discontinuing and foregoing consumer activities, which were essentially the same as those asked of the faculty in Study 1. The means for both indices showed that trained subjects were ignoring sunk costs more than untrained subjects, but only the nine-item index based on the question "Have you bought one of the following items at some time and then not used it in the past month" approached significance. Trained subjects reported that they had paid for but not used 1.14 objects and activities compared to .84 for untrained subjects, $t(78)=1.64, p=.10$.

The second section contained six questions about a range of University of Michigan issues. These questions described a particular University issue, and then asked subjects what their preferences or their actions would be. All of the questions tacitly involved sunk costs. For instance, one question asked how much rent they would need to save each month on a 10-month lease for a new apartment to forfeit a $\$ 50$ application fee they paid on a similar apartment. To get credit for a correct answer, subjects had to realize that it would be reasonable to pay a modest amount of money less each month (credit was given for \$5-10) for the second apartment to cover the second application fee and let the first apartment go.

An index was created by scoring one point for the normative response and no points for either the trap or indifference response. The trained subjects answered the policy questions more normatively $(M=3.64)$ than the untrained subjects $(M=$

6. The survey did not refer to the experiment or to the psychology department but was disguised as a consumer and opinion survey that was being conducted for local Ann Arbor merchants; the survey and the experiment were conducted by different people who were of opposite sex; and, when identifying themselves to the subjects, the experimenter affiliated himself with the University of Michigan psychology department whereas the interviewers affiliated themselves with the Research Center for Group Dynamics (RCGD).

Table 3. Mean frequency with which an alternative was chosen as an economist's response and as a personal response

\begin{tabular}{lcccc}
\hline \hline \multirow{2}{*}{$\begin{array}{c}\text { Training } \\
\text { Condition }\end{array}$} & Normative & Trap & Mixed Trap & Noneconomic \\
\cline { 2 - 5 } & & & & \\
\hline Economist's Response & 75.6 & 5.9 & 12.2 & 5.9 \\
$\quad \begin{array}{l}\text { Trained } \\
\text { Untrained }\end{array}$ & 16.9 & 41.9 & 24.4 & 15.5 \\
$\begin{array}{l}\text { Personal Response } \\
\quad \text { Trained }\end{array}$ & 44.0 & 11.1 & 30.1 & 14.2 \\
$\quad$ Untrained & 28.6 & 13.1 & 38.6 & 19.2 \\
\hline
\end{tabular}

Note. The scores are the percentage of the eight problems for which a subject chose that particular alternative as an economist's response and as a personal response. 
3.12), $t(78)=2.16, p<.05$. Five trained subjects expressed suspicion following the university policy section. Their average score for the reasoning questions was 3.4, which falls between the means of the trained and untrained groups. This suggests that demand characteristics, or subject "cooperativeness," was not responsible for the difference between trained and untrained subjects.

\section{Discussion}

Training on the normative principles substantially improved subjects' ability to identify normative reasoning. Untrained subjects thought that an economist's normative answer is the trap alternative-that is, to behave in a way that minimizes wasting resources. The untrained subjects tended personally to favor the mixed trap reasoning, which allowed them to choose the action that had the greatest net benefit (e.g., skipping the basketball game) but to rationalize it by saying that the net benefit outweighed the wasted resource (e.g., the cost of an accident far outweighed the cost of the tickets). This suggests that naive subjects do not know the sunk cost rule and instead adhere to the "waste not, want not" principle. Both in their assumptions about correct economic reasoning and in their own reasoning the untrained subjects preferred attending to past costs.

Subjects trained on the normative principles not only applied them immediately on similar problems but retained them for a full month, applying them to a different type of problem in a different context. Trained subjects also tended to differ from untrained ones in their actual behavior as well. The weak result for behavior could be due in part to the low rate at which subjects engaged in consumer activities over the brief time studied. Subjects were unlikely to have encountered a movie bad enough to leave because the average subject saw only one or two in the month following training. Recall that faculty subjects were asked about consumer behavior over a much longer time period.

\section{GENERAL DISCUSSION}

Our research shows that abstract rules are used to guide decisions about choices and that these can be altered. The reasoning of economically-naive subjects became more normative following a simple, brief training session. The fact that subjects did not require extensive direct experience with particular situations in order to give rule-consistent reasoning indicates that subjects are relying on an inferential rule and not on concrete knowledge limited to specific problems or domains. The gener alization of training from one content domain to another indicates that rules are coded at a level above that of concrete domains: Performance was as good for the untrained domain as for the trained domain. Most importantly, training improved performance on novel judgments, having content and form verj: different from training examples, one month after the training in a context quite different from that in which the training took place.

Our research indicates that knowledge of the abstract rules affects actual decisions and behaviors. The economists' data indicate that the normative rules guide reasoning, and actual choices, about activities as diverse as recommended university policy, personal career decisions, consumer behavior, and even international relations.

At the same time, the present results also make it clear that lay choice theory is fundamentally different from the normative theory. The noneconomically trained faculty were less likely to use the cost-benefit principles even when the principles were not in conflict with other principles or values. Untrained subjects in Study 3 chose the normative action-trap reasoning combination more often than the other combinations. This means that subjects were selecting the normative action but for a counternormative reason. Such reasoning seems dangerous because it suggests that, as sunk costs are increased, there will come a point at which a person will no longer choose the normative action. For instance, if the cost of the basketball tickets were high enough, the person might go to the game because the past costs would outweigh the future costs. But no matter how much money has been spent, whether it be on a game, a house, or a bomber, if the outcome will not be beneficial, the investment should be abandoned.

Our research demonstrates that, although people ordinarily are not perfectly rational by economists' standards, they are capable of becoming more rational. Before calling for the widespread teaching of these rules, however, we must note that the economic conception of rationality has been challenged by many who have doubted the appropriateness of its self-interest assumptions. A complete set of prescriptive principles of choice should include both moral and economic principles, and rules to adjudicate between the two.

Acknowledgments-The work reported here was supported by grants from the National Science Foundation (BNS-8709892 and SES-8507342), the Sloan and Russell Sage Foundations, and the Army Research Institute (MDA903-89-C-022). We thank Hal Arkes, Jonathan Baron, Paul Courant, Daniel Kahneman, and Richard Thaler for comments on earlier drafts.

\section{REFERENCES}

Allais, M. (1953). Le comportement de l'homme rationnel devant le risque: Critique des postulats et axiomes de l'Ecole americaine. Econometrica, 21, 503-546.

Arkes, H.R., \& Blumer, C. (1985). The psychology of sunk cost. Organizational Behavior and Human Decision Processes, 35, 124-140.

Becker, G. (1976). The economic approach to human behavior. Chicago: University of Chicago Press.

Brainerd, C. (1978). Piaget's theory of intelligence. Englewood Cliffs, NJ: Prentice-Hall.

Cheng, P.W., \& Holyoak, K.J. (1985). Pragmatic reasoning schemas. Cognitive Psychology, 17, 391-416.

Cheng, P.W., Holyoak, K.J., Nisbett, R.E., \& Oliver, L. (1986). Pragmatic versus syntactic approaches to training deductive reasoning. Cognitive Psychology, 18, 293-328.

Cheng, P.W., \& Nisbett, R.E. (1990. A pragmatic schema for causal deduction. Unpublished manuscript. University of California, Los Angeles.

Fong, G.T., Krantz, D.H., \& Nisbett, R.E. (1986). The effects of statistical training on thinking about everyday problems. Cognitive Psychology, 18, 253292.

Fong, G.T., \& Nisbett, R.E. (In press). Immediate and delayed transfer of training effects in statistical reasoning. Journal of Experimental Psychology: General.

Friedman, M. (1953). Essays in positive economics. Chicago: University of Chicago Press.

Hoskin, R.E. (1983). Opportunity cost and behavior. Journal of Accounting Research, 21, 78-95. 
Teaching Rules of Choice

Kahneman, D., Knetsch, J.L., \& Thaler, R.H. (In press). Experimental tests of the endowment effect and the coase theorem. Journal of Political Economy.

$\rightarrow$ Kahneman, D., \& Tversky, A. (1979). Prospect theory: An analysis of decision under risk, Econometrica, 47, 263-291.

Kunda, Z., \& Nisbett, R.E. (1986). Prediction and the partial understanding of the law of large numbers. Journal of Experimental Social Psychology, 22, 339354.

Larrick, R.P., Nisbett, R.E., \& Morgan, J.N. (1990). Who uses cost-benefit reasoning? Unpublished manuscript, University of Michigan, Ann Arbor.

$\rightarrow$ Lichtenstein, S., \& Slovic, P. (1971). Reversals of preference between bids and choices in gambling decisions. Journal of Experimental Psychology, 89, 46-55.

Mishan, E.J. (1976). Cost-benefit analysis. New York: Praeger.

Morgan, J.N., \& Duncan, G.J. (1982). Making your choices count: Economic principles for everyday decisions. Ann Arbor: University of Michigan Press $\rightarrow$

Morris, M.W., \& Nisbett, R.E. (1990). Deformation professionelle: Reasonin schemas taught in psychology and philosophy. Unpublished manuscript, University of Michigan, Ann Arbor.

Neumann, B.R., \& Friedman, L.A. (1980). The effects of opportunity costs on project investment decision: A replication and extension. Journal of Accounting Research, 18, 407-419.

Newell, A. (1980). One final word. In D.T. Tuma \& F. Reif (Eds.), Problemsolving and education: Issues in teaching and research. Hillsdale, NJ: Erlbaum.

Nisbett, R.E., Fong, G.T., Lehman, D.R., \& Cheng, P.W. (1987). Teaching reasoning. Science, 238, 625-631.

Nisbett, R.E., Krantz, D.H., Jepson, D., \& Kunda, Z. (1983). The use of statistical heuristics in everyday inductive reasoning. Psychological Review, 90 , 339-363.

Simon, H. (1955). A behavioral model of rational choice. Quarterly Journal of Economics, 69, 174-183.

Thaler, R.H. (1980). Toward a positive theory of consumer choice. Journal of Economic Behavior and Organization, 1, 39-60.

Thorndike, E.L. (1906). Principles of teaching. New York: A.G. Seiler.

Tversky, A. (1969). Intransitivity of preferences. Psychological Review, 76, 3148.

Tversky, A., \& Kahneman, D. (1981). The framing of decisions and the psychology of choice. Science, $211,453-458$.

(RECEIVED 2/26/90; REVISION ACCEPTED 5/9/90) 